\title{
The effect of smoking on the symptoms and progression of multiple sclerosis: a review
}

REVIEW

\author{
This article was published in the following Dove Press journal: \\ Journal of Inflammation Research \\ I September 2010 \\ Number of times this article has been viewed
}

\author{
Afsaneh Shirani ${ }^{\prime}$ \\ Helen Tremlett ${ }^{1,2}$ \\ 'Faculty of Medicine, Division \\ of Neurology, University of British \\ Columbia, Vancouver, Canada; ${ }^{2}$ Brain \\ Research Centre, University of British \\ Columbia, Vancouver, Canada
}

\begin{abstract}
Multiple sclerosis (MS) is a chronic inflammatory neurodegenerative disorder of the central nervous system with characteristic demyelinating lesions and axonal loss. MS accounts for the most common cause of neurological disability in young adults in the Western world. The clinical manifestations and the course of MS are highly variable. The early stage of the disease is usually characterized by attacks of neurological dysfunction with complete or incomplete recovery, however, with time disability accumulates in many patients. MS is believed to result from an interplay between susceptibility genes and environmental factors, one of which is smoking. Smoking, a worldwide epidemic, can be regarded as an important risk factor for MS particularly because of its modifiable nature in the quest to prevent or temper the disease course in MS as well as providing possible insights into MS pathogenesis. There are also reports that smoking may influence the symptoms and disease progression in patients with MS. The purpose of this article is to review the effects of smoking on MS symptoms and progression. We conclude that (1) although there are some early reports on worsening of MS symptoms by smoking, the existing evidence is insufficient to thoroughly assess the effects of smoking on the myriad of MS symptoms and (2) smoking seems to adversely influence disease progression in MS patients. We also discuss the potential biological mechanisms linking smoking and MS.
\end{abstract}

Keywords: smoking, multiple sclerosis, disease progression, symptoms

\section{Introduction}

Multiple sclerosis (MS) is primarily a chronic inflammatory disorder of the central nervous system (CNS) in which focal lymphocytic infiltrations result in damage of myelin and axons. ${ }^{1}$ Affecting around 2.5 million individuals worldwide, MS is the most common neurological disability in young adults. ${ }^{2}$ Females are affected $2-3$ times more frequently than males and clinical symptoms typically first present in the third or fourth decade of life. ${ }^{1}$ The diagnosis of MS is based on finding evidence of CNS lesions that are disseminated in time and space. The exact cause of MS is still unknown; however, it is believed that the disease results from an interplay between environmental and genetic factors. ${ }^{1}$ Some suggested environmental factors include viral infections, sunlight exposure/vitamin D deficiency, diet, and cigarette smoking. ${ }^{3} \mathrm{~A}$ positive association between smoking and the risk of developing MS has been reported. In fact, smoking is considered as an important risk factor for MS because of the strength of the evidence, its modifiable nature in the quest to prevent or temper the disease course in MS as well as providing possible insights into MS pathogenesis. ${ }^{3}$ There are also reports that smoking may influence the symptoms and progression of the disease.
Correspondence: Afsaneh Shirani Faculty of Medicine, Division of Neurology, rm SI26, UBC Hospital, 22I I Wesbrook Mall, University of British Columbia, Vancouver, BCV6T 2B5, Canada Tel + I 6048227617

Fax +l 6048227897

Email shirania@interchange.ubc.ca 
This article reviews the effects of smoking on the symptoms and progression of MS along with the possible biological mechanisms which may explain a link between smoking and MS. There are different types of tobacco consumption such as smoking, snuffing, and chewing. The focus of this article is on tobacco smoking, the most common form of which is cigarette smoking.

\section{Symptoms and course of MS}

In MS, damage to myelin results in denuded axons that are no longer able to transmit action potentials efficiently within the CNS. ${ }^{4}$ Therefore, MS can produce a wide range of symptoms reflecting the functional anatomy of impaired nerve conduction at affected sites in the CNS. ${ }^{2}$ Symptoms may include visual, motor, sensory, ataxic, autonomic, cognitive, and others. About $80 \%$ of patients present with an acute episode indicative of CNS demyelination affecting one (or occasionally several) sites known as clinically isolated syndrome (CIS). ${ }^{1}$ With time, around $30 \%-70 \%{ }^{5,6}$ of people with CIS (possible $>80 \%$ if an abnormal baseline magnetic resonance imaging $[\mathrm{MRI}]$ is present $)^{6}$ will have a subsequent relapse and thus convert to relapsing-remitting MS (RRMS) which is the most common form of the disease. ${ }^{5}$ RRMS is characterized by relapses or exacerbations followed by complete or incomplete remissions. The majority of patients with RRMS will eventually enter a progressive phase over time known as secondary progressive MS (SPMS). About $20 \%$ of patients with MS experience a continuous worsening from onset with no preceding relapse known as primary progressive MS (PPMS). ${ }^{1}$

\section{MS as an inflammatory disease}

The sequence of events that initiate MS is not yet known and more than one pathogenetic mechanism is likely to contribute to tissue injury. ${ }^{4}$ However, it is largely believed that inflammation, at least in part mediated by autoimmunity, drives the pathogenesis of MS. ${ }^{7}$ One of the earliest events in the pathogenesis of MS is the migration of autoreactive $\mathrm{T}$ cells (directed against components of myelin) across the blood-brain barrier (BBB), the vascular shield which helps to regulate and protect the microenvironment of the brain. ${ }^{1}$ Within the CNS and upon recognition of myelin-derived peptides on major histocompatibility complex molecules on the surface of antigen presenting cells, autoreactive $\mathrm{T}$ cells become reactivated and contribute to initiating inflammatory cascades by producing cytokines and chemokines, and recruiting other immune cells such as macrophages and B lymphocytes into the lesions. ${ }^{7,8}$ Endothelial adhesion molecules mediate the recruitment of immune cells into the CNS, and proteases particularly matrix metaloproteinases facilitate the migration of inflammatory cells into and within the CNS. ${ }^{7}$ Chronic CNS inflammation leads to demyelination and subsequent axonal damage. There is also evidence of axonal damage in the early stages of MS, ${ }^{9}$ and it could be implied both through pathological and epidemiological studies that axonal damage may occur independently of inflammation in MS. ${ }^{10-14}$ Other recent studies, however, suggest that axonal injury is pathologically invariably associated with inflammation, especially in progressive MS, ${ }^{15}$ and that demyelination contributes to axonal density with a greater magnitude in PPMS compared with SPMS. ${ }^{16}$ Therefore, it remains to be determined if inflammation is primary or secondary to a neurodegenerative process in MS brains. ${ }^{17}$ In addition, pathogenic heterogeneity in immune effector mechanisms involved in MS lesion formation has been reported, ${ }^{18}$ although this was challenged by another study. ${ }^{19}$

\section{Epidemiologic considerations}

More than 1.3 billion people smoke cigarettes worldwide, and each year, about 30 million people become new smokers. ${ }^{20,21}$ Tobacco smoking is one of the main preventable causes of chronic disease and death. Smoking, as an environmental factor, is associated with increased risk of some autoimmune diseases such as rheumatoid arthritis, systematic lupus erythematosus, Graves' hyperthyroidism, primary biliary cirrhosis, and possibly MS. ${ }^{22}$ It has also been shown that individuals with disabilities are more likely to have ever smoked and to be current smokers. ${ }^{23}$

A positive association between smoking and risk of MS has been suggested in some large prospective cohorts including the United Kingdom's Oxford Family Planning Association Study, the Royal College of General Practitioners' Oral Contraceptive Study, the General Practice Research Database Study, and the USA's Nurses Health Study and Nurses Health Study II. ${ }^{3}$ A summary estimate showed a relative risk of $1.6(95 \% \mathrm{CI}, 1.3-1.9)$ for the development of MS in heavy smokers. ${ }^{3}$ In addition, children exposed to parental smoking at home have been found to have a higher risk of childhood-onset MS. ${ }^{24}$ Although confounding cannot be excluded, the existing evidence suggests that smoking does increase the risk for MS. ${ }^{3}$ According to recent reports, there is an alarming rise in the rate of smoking among young women worldwide. ${ }^{25}$ This is while women are at increased risk of developing MS compared with men and there are even some reports that female to male sex ratio in MS has increased over the last decades. ${ }^{26,27}$ It remains to be investigated whether 
the increase in female smokers is linked with the increase in female to male ratio in MS patients.

\section{Smoking and acute worsening of MS symptoms}

Tobacco smoking was recognized, as early as the 19th century, as a cause of bilateral optic neuropathy. ${ }^{28}$ It was suggested in a self-report-based case series from the 1960s that during an MS relapse, patients appear to be unusually sensitive to the central effects of smoking during or shortly after smoking. ${ }^{29}$ This may result in accentuation of the cerebral symptoms such as mental confusion, blurred or double vision, vertigo and or ataxia, paresthesia, and motor weakness as well as general symptoms such as lassitude and fatigue. ${ }^{29}$ In a study assessing the effect of smoking on the recovery of visual function after an attack of optic neuritis (a common presentation of MS in which inflammation of the optic nerve causes unilateral painful blurring or loss of vision), heavy smokers were found to have a higher incidence of red/green color vision defects than nonsmokers. ${ }^{30}$ A transient worsening of upper extremity motor performance immediately after smoking has also been described in MS patients. ${ }^{31}$ An explanation for the increased sensitivity to cigarette smoking in MS patients could be that a compromised CNS with limited reserve may have increased vulnerability to alterations in its state of balance. ${ }^{31}$ Yet, a thorough and systematic investigation of the effects of smoking on MS symptoms remains to be done.

\section{Smoking and chronic progression of MS}

A summary of the studies which have examined the relationship between smoking and MS progression is shown in Table 1. Cigarette smoking has been suggested to adversely influence the progression of MS and accelerates transition from a relapsing-remitting course to a progressive course. ${ }^{32-35}$ The largest study to date investigating the effects of smoking on MS progression included 1,465 MS patients, ${ }^{35}$ and found that current smokers were more than twice as likely to have PPMS than people with MS who never smoked. This was supported by another study which not only showed that MS patients who ever smoked were twice as likely to have the progressive form of the disease, but also reported that people with early smoking debut ( $\leq 15$ years of age) were more likely to be diagnosed with progressive disease. ${ }^{32}$ Recently, smoking has been reported to be associated with some MRI markers of disease progression such as increased lesion burden and greater brain atrophy. ${ }^{36}$ Smoking has also been shown to be a risk factor for conversion from CIS to clinically definite MS. ${ }^{37}$ In a study in Groningen, the Netherlands, smoking was not associated with the rate of conversion from RRMS to SPMS or with time from MS onset to fixed disability milestones (as measured by the Expanded Disability Status Scale [EDSS]). ${ }^{38}$ The reason for the conflicting result between this study and the other studies is not clear; however, a potential source of bias might relate to the Groningen's study setting (hospitalbased) and its retrospective nature; a substantial proportion of patients had died or could not be contacted to complete the smoking questionnaire which was sent out over 20 years after recruitment of the first patients into the database. ${ }^{35}$ In a 3-year prospective Tasmanian cohort study (Australia), smoking was positively associated with the progression of clinical disability, but was not associated with the likelihood of developing a relapse among RRMS patients. ${ }^{33}$ In the same study, smoking was associated with an increased risk of a progressive course at MS onset rather than a relapsingremitting course. In summary, the majority of the studies which have investigated the relationship between smoking and MS progression suggest that smoking adversely influences the progression or course of the disease.

\section{Potential biological mechanisms linking smoking and MS}

A burning cigarette generates more than 4,500 chemical compounds many of which have various toxic, mutagenic, and carcinogenic effects. ${ }^{39}$ Moreover, compounds found in cigarette smoke go through complex chemical reactions. ${ }^{40}$ It is not clear how smoking may affect MS symptoms and progression, or increase the risk of developing MS. However, some potential mechanisms, briefly reviewed below, can be suggested.

\section{Chronic cyanide intoxication}

Inhaled tobacco smoke is a major source of hydrogen cyanide. ${ }^{41}$ The levels of cyanide and its main metabolite, thiocyanate, ${ }^{42}$ are strongly correlated with the amount of smoking. ${ }^{42}$ Cyanide has been shown to induce selective demyelination in animal models. ${ }^{43-49}$ Demyelinative lesions were produced more successfully if repeated rather smaller doses of cyanide were administered, than one single large dose.$^{50}$ Corpus callosum is an area of white matter susceptible to cyanide damage. ${ }^{51}$ Interestingly, the corpus callosum is also fairly likely to be attacked in $\mathrm{MS} .{ }^{52}$ Considering all these findings, it is possible that smoking affects MS through cyanide encephalopathy. 


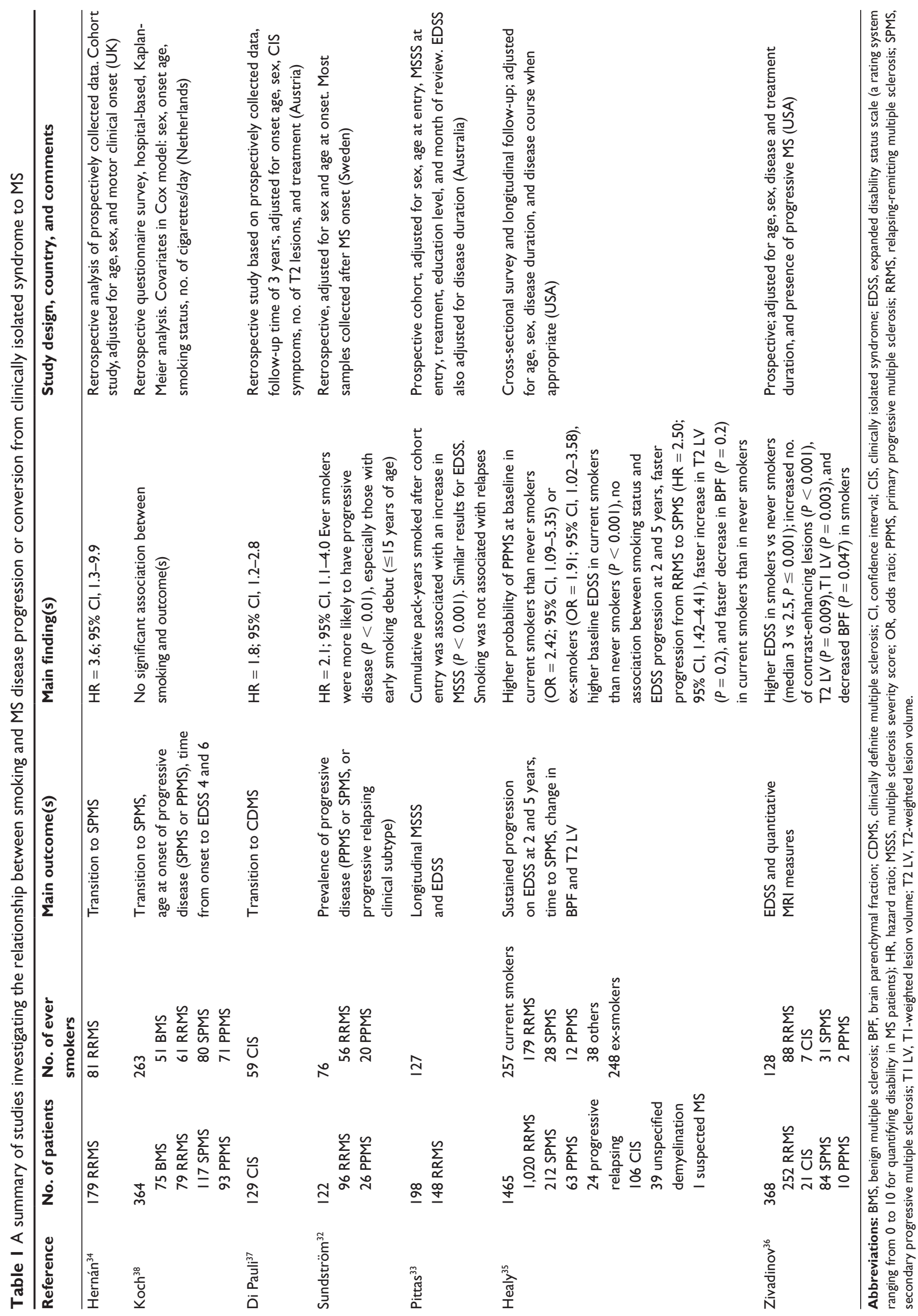




\section{Dysregulation of the blood brain barrier}

Dysregulation of the BBB and transendothelial migration of autoreactive lymphocytes might be among the earliest abnormalities seen in the disease process of MS and appear to parallel the release of inflammatory cytokines/ chemokines. ${ }^{1,53}$ Nicotine has been shown to increase local cerebral microvascular blood flow ${ }^{54,55}$ and to raise the influx of permeable solutes across the BBB in rats. ${ }^{56} \mathrm{In}$ fact, nicotine leads to changes in BBB permeability via the modulation of tight junction proteins.$^{57}$ It is, therefore, possible that smoking be related to MS through direct effects of nicotine or other cigarette smoke components on the BBB..$^{34,42}$ Recently, the role of nicotine in increasing the risk of developing MS among smokers has been questioned by a case-control study showing that tobacco smoking, but not Swedish snuff (also containing nicotine) elevates the risk of MS. ${ }^{58}$

\section{Immunomodulatory effects}

Cigarette smoke may have mixed effects on the immune system. Nicotine, a major constituent of cigarette smoke, has been shown to suppress the T-cell response, ${ }^{59}$ and to affect the differentiation, phenotype, and function of antigen presenting cells. ${ }^{60-62}$ However, nicotine might also have therapeutic potential as a neuroprotective and anti-inflammatory agent. ${ }^{39}$ In addition, tobacco glycoprotein, a polyphenol-rich glycoprotein purified from tobacco leaves and present in cigarette smoke condensate, has been shown to stimulate the proliferation of human peripheral $\mathrm{T}$ cells and the differentiation of B cells. ${ }^{63}$ In the murine experimental autoimmune encephalomyelitis (EAE) model of MS, nicotine exposure was shown to delay and attenuate CNS inflammation and autoimmune responsiveness to myelin antigen. ${ }^{64}$ Another component of cigarette smoke, acrolein, has been associated with immunosupression and proposed to produce neurodegeneration. ${ }^{32}$ Cigarette smoking has also been associated with increased expression of Fas (a cell surface molecule with an important role in immune homeostasis and cytotoxic activity) on $\mathrm{B}$ and $\mathrm{CD} 4^{+} \mathrm{T}_{\text {lymphocytes. }}{ }^{65}$ In addition, cigarette smoking has antiestrogenic effects which may affect the $\mathrm{T}$ helper $1 / \mathrm{T}$ helper 2 balance. ${ }^{36} \mathrm{An}$ immunomodulatory link can be hypothesized between MS and smoking; however, the involved mechanisms are not yet clear. In addition, the qualitative and quantitative aspects of the effects of smoking on the immune system might be related to smoking duration, as well as the sex and ethnicity of the studied subjects. ${ }^{39}$

\section{Inflammatory effects}

Cigarette smoke has been reported to have inflammatory effects such as increasing peripheral leukocyte counts, and recruitment of polymorphonuclear cells, monocytes, and macrophages. ${ }^{22}$ It has also been shown to increase levels of C-reactive protein (CRP), interleukin-6 (IL-6), serum intercellular adhesion molecule 1 (ICAM-1), and E-selectin. ${ }^{22}$ CRP and IL-6 are important inflammatory markers in autoimmune diseases, ${ }^{66,67}$ and ICAM-1 and E-selectin are two endothelial adhesion molecules whose CNS expression may be up-regulated in MS to facilitate the entry of $\mathrm{T}$ cells into the CNS. ${ }^{4}$ It is thus possible that smoking affects MS through its inflammatory properties.

Complement activation plays an important role in the inflammatory response. A possible role for the complement system in MS has been proposed based on the demonstration of complement activation products in the MS brain and biological fluids. ${ }^{68}$ Complement component 3 (C3) deposits have been described in the brains of MS patients. ${ }^{69}$ Increased levels of serum complement component 5b-9 (C5b-9, the "terminal membrane attack complex") have been reported in the cerebrospinal fluid (CSF) of MS patients during attacks. These levels have also been shown to correlate with the degree of neurological disability. ${ }^{70}$ However, it has been shown that during demyelination, activation of complement and C5b-9 assembly may have neuroprotective effects by protecting oligodendrocytes from apoptosis. ${ }^{70}$ Cigarette smoke can affect complement activation by increasing CRP levels and inducing C3a and C5a. ${ }^{71,72}$ It can thus be hypothesized that smoking may influence the role of complement in the inflammatory response in MS patients, although the exact mechanism(s) remain to be determined.

\section{Nitric oxide}

Nitric oxide (NO) is a free radical signaling molecule with a complex biochemistry produced from the amino acid arginine by the enzymatic action of NO synthases (NOS) ${ }^{73}$ In addition to its role in regulating vessel tone, NO plays an important role in host defense and immunity including the modulation of inflammatory responses. ${ }^{74} \mathrm{NO}$ has also been reported to cause axonal degeneration or block axonal conduction especially in physiologically active or demyelinated axons. ${ }^{75-77}$ Axonal degeneration makes a major contribution to permanent neurological disability in MS. Axons undergo degeneration particularly at the site of the inflammatory damage, suggesting that locally produced inflammatory factors, such as NO may play a role in mediating axonal degeneration in MS. ${ }^{75}$ iNOS is the high-output isoform of 
NOS. ${ }^{73}$ The codistribution of iNOS and nitrotyrosine (the product of peroxynitrite-mediated nitration of tyrosine) in active MS lesions has been demonstrated. ${ }^{78}$ iNOS has been shown to be expressed in multiple cell types in active MS lesions, and astrocyte iNOS has been suggested to contribute to vasodilation and damage to the BBB besides its immunoregulatory role. ${ }^{79}$ Elevated levels of $\mathrm{NO}$ metabolites in the CSF have been reported in MS and were found to correlate with the volume of gadolinium-enhanced lesions on MRI. ${ }^{80}$ Cigarette smoke contains various free radicals including NO. ${ }^{81}$ Increased NO plasma levels in smokers have also been reported in several studies, ${ }^{82-84}$ although not confirmed in all studies. ${ }^{85}$ It might thus be hypothesized that smoking may increase NO concentration at sites of MS inflammatory lesions and contribute to axonal degeneration. ${ }^{34}$

\section{Infections}

It is well established that smoking increases the frequency and persistence of respiratory infections. ${ }^{86}$ An increased risk of MS exacerbations during respiratory infections has been reported. ${ }^{87-90}$ It has also been found that exacerbations around the time of a clinical infection lead to more sustained neurological damage than noninfection-associated exacerbations. ${ }^{91}$ An association between Chlamydia pneumonia (C pneumonia) infection and MS has been described, ${ }^{92,93}$ although not confirmed. ${ }^{94,95}$ C pneumonia-specific antibodies have been found to be higher in smokers than in nonsmokers. ${ }^{96,97}$ Smoking, therefore, could be linked to MS by increasing respiratory infections. Furthermore, a positive association between levels of antibodies to Epstein-Barr virus (EBV), a virus which has been repeatedly associated with MS in epidemiological and serological studies, ${ }^{98}$ and tobacco smoking has been reported. ${ }^{99}$ Recently, the immunoglobulin G antibody to EBV nuclear antigen 1 has been suggested as a marker of disease activity based on the correlation between antibody levels and gadolinium-enhancing lesions on brain MRI of MS patients. ${ }^{100}$

\section{Modulation of matrix metalloproteinase}

Matrix metaloproteinases are important contributors to the inflammatory damage at the level of the BBB in MS pathogenesis. ${ }^{101}$ They enhance the migration of autoreactive immune cells into CNS by degrading extracellularmatrix macromolecules. ${ }^{4}$ An increased serum level of metalloproteinase 9 (gelatinase B) in MS patients has been shown in some studies. ${ }^{101}$ This increase was found to be associated with more gadolinium-enhancing MRI lesions. ${ }^{102}$ Cigarette smoking was also found to be associated with an elevation in serum metalloproteinase 9 levels. ${ }^{103}$ It may thus be speculated that smoking may affect MS by modulation of matrix metalloproteinase 9.

\section{Iron overload}

Iron is essential for myelin formation, function of the immune effector cells, and oxidative phosphorylation. ${ }^{104}$ The importance of iron for brain function is reflected by the presence of receptors for transferrin on brain capillary endothelial cells. ${ }^{105}$ Iron is also thought to contribute to oxidative damage in pathological conditions through catalyzing the formation of hydroxyl radicals, ${ }^{106,107}$ and causing secondary initiation of lipid peroxidation. ${ }^{108,109}$ Oxidative damage has been implicated in several neurological diseases including MS. Chronic smoking can lead to iron overload. In fact, tissue hypoxia from smoking results in erythrocytosis and increased production of erythropoietin which consequently increases the red cell mass. ${ }^{110}$ This in turn augments cell turnover and the number of red blood cells destroyed, resulting in iron overload. ${ }^{111}$ Cigarette smoke also contains toxic heavy metals such as mercury, cadmium, manganese, and lead. ${ }^{12,113}$ In addition to potential neurotoxicity, ${ }^{114}$ accumulation of these toxic metal species may result in disturbance of iron metabolism in astrocytes and in the brain. ${ }^{15}$ Astrocytes are specialized to serve as depots of toxic metals, ${ }^{116}$ and divalent metals have been shown to compete with ferrous iron $\left(\mathrm{Fe}^{2+}\right)$ for the divalent metal transporter 1 , a major $\mathrm{Fe}^{2+}$ transporter mediating cellular iron uptake. ${ }^{115}$ Therefore, these metals have the potential to dysregulate iron metabolism in the brain. Some lines of evidence suggest a role for iron in MS inflammation. Significant increases in mean serum ferritin in MS patients over controls have been reported. ${ }^{104,117}$ Iron overload in MS plaques has been demonstrated in vivo by MRI. ${ }^{118}$ Also high iron concentrations have been found in oligodendrocytes, myelin, reactive myelin, and macrophages in MS lesions. ${ }^{119,120}$ The cause of iron accumulation in MS is unknown and it is not clear whether iron overload leads to the damage or results from the damage in MS. ${ }^{104}$ Although further studies are needed to investigate the role of iron in MS pathogenesis, it may be conceivable that cigarette smoking affects MS by contributing to iron overload.

\section{Venous pathology}

A topographic correspondence between the MS plaque and the cerebral venous system has been reported in postmortem neuropathological studies and MR venography. ${ }^{121-123}$ Histologic examination of the involved 
veins has shown aspects of impaired venous drainage such as perivenous iron deposits and fibrin cuffs, particular to chronic venous insufficiency. ${ }^{124}$ Recently, a high incidence of chronic cerebrospinal venous insufficiency (CCSVI), a vascular picture characterized by the stenosis of the main extracranial cerebrospinal veins, the jugular and azygous system, and by the opening of substitute circles, has been described in MS patients by Zamboni et al ${ }^{123,125}$ (although the prevalence of smoking which could represent a confounding factor was not reported). Some discrepancies in the prevalence of CCSVI have been reported, in MS cases and healthy controls alike, between Zamboni et al's Italian study vs Zivadinov et al's ${ }^{126}$ North American (Buffalo) study. Indeed, this field of investigation is expanding rapidly, further clarification of the possible association or dissociation between MS and CCSVI is likely forthcoming. Smoking is reported to be significantly associated with lower limb venous insufficiency. The mechanisms leading to harmful effects of tobacco on the venous system are still not elucidated. ${ }^{127}$ However, cigarette smoking is believed to be a major factor in hypoxia through carbon monoxide and NO fixation in hemoglobin. ${ }^{127,128}$ It has been hypothesized that the effect of hypoxia on the functional state of the endothelium can be the starting point of a cascade of events leading to disorganization of the vessel typical of venous pathologies such as varicose veins. Hypoxia activates the endothelial cells, resulting in the production of proinflammatory factors within the vessel wall, increased capillary permeability and local inflammatory changes. ${ }^{129}$ Endothelial basal lamina has been found thickened in heavy smokers and the thickening contained fibronectin. ${ }^{130}$ It has also been reported that heavy smokers have impaired release of endothelium-derived relaxing factor in response to bradykinin and calcium ionophore. This impairment may increase vasomotor tone and smooth muscle proliferation in veins. ${ }^{131}$ Even the implication of a developmental origin in venous anomalies seen in CCSVI ${ }^{132}$ does not exclude the possibility that smoking could contribute to the venous flow abnormalities. It can thus be speculated that smoking may be related to venous MS hypothesis through harmful effects of tobacco on the venous system and its hemodynamics.

\section{Vitamin D}

A link between vitamin D and MS has been supported by several lines of evidence including lower prevalence of MS where there is more sun, reduced risk of MS with adequate sunlight or vitamin D supplementation, and association of lower levels of vitamin D with greater risk of relapse. ${ }^{133}$ A population-based survey in Switzerland showed that female current smokers had lower dietary intake of vitamin D than nonsmokers $(1.92 \mu \mathrm{g} /$ day in heavy smokers vs $2.39 \mu \mathrm{g} /$ day in never smokers; $P=0.0003) .{ }^{134}$ Another cross-sectional study on females in Denmark showed that smokers as compared with nonsmokers had significantly reduced levels of $25(\mathrm{OH})$ vitamin D and $1,25(\mathrm{OH})_{2}$ vitamin D. ${ }^{135}$ Although several potential confounders may explain why smokers may differ from nonsmokers with respect to serum 25-hydroxyvitamin D levels, it can be speculated that smoking may contribute to the potential adverse effects of vitamin D deficiency in MS patients. Low serum $25(\mathrm{OH})$ vitamin D levels or low levels of sunlight might also contribute to an increased risk of upper respiratory tract infections and hence elevate the risk of an MS relapse. ${ }^{136}$

\section{Other lifestyle factors and comorbidities}

Smokers appear more likely to have coexisting comorbidities or engage in other lifestyle habits which might confound the relationship between smoking and MS. For instance, tobacco smokers are more likely to consume alcohol and caffeine and exercise less. ${ }^{137,138} \mathrm{~A}$ higher intake of caffeine-containing beverages, such as tea or coffee, in the period from infancy to adolescence, has been reported in MS cases compared with controls. ${ }^{139}$ Consumption of hard liquor, but not wine or beer, was significantly associated with an increased risk of developing MS. ${ }^{140}$ Although a questionnaire study showed that alcohol consumption was associated with lower disability scores,${ }^{141}$ reverse causation cannot be ruled out, with perhaps reduced mobility and worsening bladder problems limiting a person's desire to drink.

Higher levels of exercise have been associated with lower disability scores and improved cognition in MS. ${ }^{142}$ Although causation again has yet to be shown, exercise might confound the relationship between smoking and MS. The diet of smokers has also been reported as being less healthy, characterized by a lower intake of vegetables, fruits, vitamins, dietary fiber, and polyunsaturated fat compared with nonsmokers. ${ }^{138,143}$ Some ecological studies have suggested that diets high in animal/saturated fat and low in polyunsaturated fats may increase the risk of MS. ${ }^{3}$ Although a prospective study of dietary fat found neither animal nor saturated fats to be associated with an increased risk of MS. However, a nonsignificant, reduced risk of MS was associated with a higher intake of $n-3$ polyunsaturated linolenic acid. ${ }^{144}$ Slight decreases in relapse rate and relapse severity were 
associated with $\omega-6$ fatty acids in some small studies. ${ }^{145}$ No significant associations between risk of MS and intakes of fruits, vegetables, vitamin C, vitamin E, or multivitamin supplements have been found. ${ }^{146}$

Some associations between body mass index (BMI) and smoking have been described. Although mean BMI tended to be lower in smokers when compared with nonsmokers, an increased level of smoking was found to be positively associated with BMI among smokers, particularly in men. ${ }^{147}$ In addition, obese adolescents have been found to have an increased risk of developing MS. ${ }^{148}$ Smokers appear at greater risk of comorbidities such as depression. ${ }^{149}$ High rates of depression have also been described in MS patients with a lifetime prevalence as high as $50 \% .{ }^{150}$ Comorbidities such as vascular and mental comorbidities (including depression) and obesity were associated with a greater degree of disability at MS diagnosis and longer delays in the time between onset symptoms and diagnosis. ${ }^{151}$ Smoking is a risk factor for many vascular disorders. Vascular comorbidities have also been found to increase the risk of disability progression in MS. ${ }^{152}$ Further studies are needed to investigate how smoking may interact with lifestyle factors and comorbidities in MS patients.

\section{ApoE polymorphism modulation}

Apolipoprotein E (ApoE), is an important carrier in transporting lipid, a major constituent of myelin. ApoE has been suggested to have a significant role in remodeling and repair of nerve tissue, and in modifying systemic and brain inflammatory responses. ${ }^{153,154}$ It is controversial whether ApoE polymorphism influences MS susceptibility or clinical severity. The risk associated with the ApoE polymorphism has been reported to be modulated by smoking in several diseases such as Alzheimer's disease. ${ }^{155}$ Although many tobacco ingredients or smoke-related metabolites have toxic effects on CNS, nicotine might have some potential neuroprotective and anti-inflammatory properties. ${ }^{39}$ Nicotine has been suggested to have systematic immunosuppressive effects, and to inhibit microglial activation and leukocyte recruitment during inflammatory processes. ${ }^{154}$ The main mediators of these effects are $\alpha 7$ nicotinic cholinergic receptors. A protective influence of smoking on disease progression in female MS patients carrying the ApoE E4 isoform has been reported. ${ }^{154}$ Although this finding needs confirmation, authors speculated that in MS patients, smoking may counterbalance the ApoE E4-associated promotion of brain tissue damage by facilitating nicotinic cholinergic function. ${ }^{154}$

\section{Advanced glycation end products (AGEs) and their receptors}

AGEs are a complex and heterogeneous group of reactive compounds formed from the nonenzymatic reaction of reducing sugars with the free amino groups of proteins, lipids, and nucleic acids. ${ }^{156}$ AGEs may bind to specific cell surface receptors such as the receptor for advanced glycation end products (RAGE), generate reactive oxygen species, and form crosslinks. ${ }^{157}$ RAGE is present on lymphocytes, mononuclear phagocytes, and vascular endothelial cells. ${ }^{158}$ Besides AGEs, RAGE can also bind to other ligands such as amyloid $\beta$-peptide, S100 proteins, and amphoterin. ${ }^{159}$ Ligand/RAGE interactions may lead to enhanced production of proinflammatory cytokines through the activation of many cell signaling pathways. ${ }^{160}$ Enhanced expression of RAGE has been found in neurons and inflammatory cells in immunohistological studies of spinal cord tissue of MS patients compared with healthy controls. ${ }^{161}$ In addition, blockage of RAGE has been shown to suppress EAE. ${ }^{161}$ Soluble RAGE (sRAGE) is an isoform of RAGE that is believed to act as a decoy, preventing deleterious effects of AGE/RAGE signaling by binding to RAGE ligands. ${ }^{162}$ Serum levels of sRAGE were shown to be significantly lower in MS patients compared with healthy controls. ${ }^{160}$ These findings may imply a potential role for the RAGE axis in the pathogenesis of MS. Tobaccoderived reactive glycation products capable of promoting AGE formation have been identified in tobacco smoke, and serum AGE levels were found to be significantly higher in cigarette smokers than in nonsmokers. ${ }^{163}$ Based on these lines of evidence, it can be hypothesized that smoking may affect MS through the AGE-RAGE axis. This could be a potential avenue for future research.

\section{Conclusions and future directions}

The majority of studies investigating the influence of smoking on disease progression or development of the progressive course in MS have shown a significantly adverse effect of smoking on different outcome measures. Smoking should thus be considered as a modifiable risk factor for MS progression. Although it remains to be investigated whether smoking cessation (aside from the well recognized other health benefits) will actually slow down the more rapid MS progression associated with smoking, and how long this effect might take place once a person quits. Whether exposure to secondhand smoke has the same negative effects on MS progression is not yet known, although it may modify (increase) the risk of developing childhood MS. ${ }^{24}$ Possible worsening 
of MS symptoms has been associated with smoking, but these findings need to be confirmed and the possible impact of smoking on the vast myriad of MS symptoms further evaluated. Further studies are needed to investigate the "dose response" (acute vs chronic) effects of smoking and MS. In addition, reverse causality should be considered, as MS onset or MS symptoms might influence smoking habits. It also remains to be assessed whether smoking may affect an MS patient's response to immunomodulatory therapy. Several potential biological mechanisms describing how smoking may be linked to MS can be suggested; however, the association between smoking and MS is subjected to numerous confounders, as mentioned throughout this review, making it difficult to verify the actual nature of the association, and how or whether it truly affects disease activity or progression. A better understanding of the mechanisms underlying the possible links between smoking and MS may provide new insights into the etiology and the pathogenesis of MS.

\section{Acknowledgment}

We would like to acknowledge the reviewers from the Journal of Inflammation Research for their constructive comments.

\section{Disclosure}

A.S. is funded through grants from the Canadian Institute of Health Research (MOP-93646; PI=H.T.) and the National Multiple Sclerosis Society (RG 4202-A-2; PI=H.T.). H.T. is funded by the MS Society of Canada (Don Paty Career Development Award) and is a Michael Smith Foundation for Health Research Scholar.

\section{References}

1. Compston A, Coles A. Multiple sclerosis. Lancet. 2008;372(9648): 1502-1517.

2. Compston A, Coles A. Multiple sclerosis. Lancet. 2002;359(9313): 1221-1231.

3. Ascherio A, Munger KL. Environmental risk factors for multiple sclerosis. Part II: noninfectious factors. Ann Neurol. 2007;61(6):504-513.

4. Noseworthy JH, Lucchinetti C, Rodriguez M, Weinshenker BG. Multiple sclerosis. N Engl J Med. 2000;343(13):938-952.

5. Miller D, Barkhof F, Montalban X, Thompson A, Filippi M. Clinically isolated syndromes suggestive of multiple sclerosis, part I: natural history, pathogenesis, diagnosis, and prognosis. Lancet Neurol. 2005;4(5):281-288.

6. Fisniku LK, Brex PA, Altmann DR, et al. Disability and T2 MRI lesions: a 20-year follow-up of patients with relapse onset of multiple sclerosis. Brain. 2008;131(Pt 3):808-817.

7. Lassmann H. Mechanisms of multiple sclerosis. Drug Discov Today Dis Mech. 2005;2(4):447-452.

8. Gran B, Rostami A. T cells, cytokines, and autoantigens in multiple sclerosis. Curr Neurol Neurosci Rep. 2001;1(3):263-270.
9. de Stefano N, Narayanan S, Francis GS, et al. Evidence of axonal damage in the early stages of multiple sclerosis and its relevance to disability. Arch Neurol. 2001;58(1):65-70.

10. Maggs FG, Palace J. The pathogenesis of multiple sclerosis: is it really a primary inflammatory process? Mult Scler. 2004;10(3): 326-329.

11. Confavreux C, Vukusic S, Adeleine P. Early clinical predictors and progression of irreversible disability in multiple sclerosis: an amnesic process. Brain. 2003;126(Pt 4):770-782.

12. Weinshenker BG, Rice GP, Noseworthy JH, Carriere W, Baskerville J, Ebers GC. The natural history of multiple sclerosis: a geographically based study. 3. Multivariate analysis of predictive factors and models of outcome. Brain. 1991;114(Pt 2):1045-1056.

13. Tremlett H, Yousefi M, Devonshire V, Rieckmann P, Zhao Y. Impact of multiple sclerosis relapses on progression diminishes with time. Neurology. 2009;73(20):1616-1623.

14. Scalfari A, Neuhaus A, Degenhardt A, et al. The natural history of multiple sclerosis, a geographically based study 10: relapses and longterm disability. Brain. 2010;133(Pt 7):1914-1929.

15. Frischer JM, Bramow S, Dal-Bianco A, et al. The relation between inflammation and neurodegeneration in multiple sclerosis brains. Brain. 2009;132(Pt 5):1175-1189.

16. Tallantyre EC, Bo L, Al-Rawashdeh O, et al. Greater loss of axons in primary progressive multiple sclerosis plaques compared to secondary progressive disease. Brain. 2009;132(Pt 5):1190-1199.

17. Trapp BD, Nave KA. Multiple sclerosis: an immune or neurodegenerative disorder? Annu Rev Neurosci. 2008;31:247-269.

18. Lucchinetti C, Bruck W, Parisi J, Scheithauer B, Rodriguez M, Lassmann H. Heterogeneity of multiple sclerosis lesions: implications for the pathogenesis of demyelination. Ann Neurol. 2000;47(6): 707-717.

19. Barnett MH, Prineas JW. Relapsing and remitting multiple sclerosis: pathology of the newly forming lesion. Ann Neurol. 2004;55(4): 458-468.

20. Jha P. Avoidable global cancer deaths and total deaths from smoking. Nat Rev Cancer. 2009;9(9):655-664.

21. Wipfli H, Samet JM. Global economic and health benefits of tobacco control: part 1. Clin Pharmacol Ther. 2009;86(3):263-271.

22. Costenbader KH, Karlson EW. Cigarette smoking and autoimmune disease: what can we learn from epidemiology? Lupus. 2006;15(11): 737-745.

23. Brawarsky P, Brooks DR, Wilber N, Gertz RE Jr, Klein Walker D. Tobacco use among adults with disabilities in Massachusetts. Tob Control. 2002;11 Suppl 2:ii29-ii33.

24. Mikaeloff Y, Caridade G, Tardieu M, Suissa S. Parental smoking at home and the risk of childhood-onset multiple sclerosis in children. Brain. 2007;130(Pt 10):2589-2595.

25. World Health Organization. Women and the tobacco epidemic: challenges for the 21st century. WHO: Canada; 2001.

26. Orton SM, Herrera BM, Yee IM, et al. Sex ratio of multiple sclerosis in Canada: a longitudinal study. Lancet Neurol. 2006;5(11): 932-936.

27. Alonso A, Hernan MA. Temporal trends in the incidence of multiple sclerosis: a systematic review. Neurology. 2008;71(2):129-135.

28. Kesler A, Pianka P. Toxic optic neuropathy. Curr Neurol Neurosci Rep. 2003;3(5):410-414.

29. Courville CB, Maschmeyer JE, Delay CP. Effects of smoking on the acute exacerbations of multiple sclerosis. Bull Los Angel Neuro Soc. 1964;29:1-6.

30. Perkin GD, Bowden P, Clifford R. Smoking and optic neuritis. Postgrad Med J. 1975;51:382-385.

31. Emre M, de Decker C. Effects of cigarette smoking on motor functions in patients with multiple sclerosis. Arch Neurol. 1992;49(12): 1243-1247.

32. Sundstrom P, Nystrom L. Smoking worsens the prognosis in multiple sclerosis. Mult Scler. 2008;14(8):1031-1035. 
33. Pittas F, Ponsonby AL, van der Mei IA, et al. Smoking is associated with progressive disease course and increased progression in clinical disability in a prospective cohort of people with multiple sclerosis. J Neurol. 2009;256(4):577-585.

34. Hernan MA, Jick SS, Logroscino G, Olek MJ, Ascherio A, Jick H. Cigarette smoking and the progression of multiple sclerosis. Brain. 2005;128(Pt 6):1461-1465.

35. Healy BC, Ali EN, Guttmann CR, et al. Smoking and disease progression in multiple sclerosis. Arch Neurol. 2009;66(7):858-864.

36. Zivadinov R, Weinstock-Guttman B, Hashmi K, et al. Smoking is associated with increased lesion volumes and brain atrophy in multiple sclerosis. Neurology. 2009;73(7):504-510.

37. Di Pauli F, Reindl M, Ehling R, et al. Smoking is a risk factor for early conversion to clinically definite multiple sclerosis. Mult Scler. 2008;14(8):1026-1030.

38. Koch M, van Harten A, Uyttenboogaart M, de Keyser J. Cigarette smoking and progression in multiple sclerosis. Neurology. 2007; 69(15):1515-1520.

39. Sopori M. Effects of cigarette smoke on the immune system. Nat Rev Immunol. 2002;2(5):372-377.

40. Rennard SI. Cigarette smoke in research. Am J Respir Cell Mol Biol. 2004;31(5):479-480.

41. Way JL. Cyanide intoxication and its mechanism of antagonism. Annu Rev Pharmacol Toxicol. 1984;24:451-481.

42. Hernan MA, Olek MJ, Ascherio A. Cigarette smoking and incidence of multiple sclerosis. Am J Epidemiol. 2001;154(1):69-74.

43. Hicks SP. Brain metabolism in vivo; the distribution of lesions caused by cyanide poisoning, insulin hypoglycemia, asphyxia in nitrogen and fluoroacetate poisoning in rats. AMA Arch Pathol. 1950;49(2):111-137.

44. Ibrahim MZ, Briscoe PB Jr, Bayliss OB, Adams CW. The relationship between enzyme activity and neuroglia in the prodromal and demyelinating stages of cyanide encephalopathy in the rat. $J$ Neurol Neurosurg Psychiatry. 1963;26:479-486.

45. Levine S, Geib LW. Leukoencephalopathy in a cat due to accidental cyanide poisoning. Pathol Vet. 1966;3(3):190-195.

46. Levine S, Stypulkowski W. Experimental cyanide encephalopathy. $A M A$ Arch Pathol. 1959;67(3):306-323.

47. Levine S, Wenk EJ. Cyanide encephalopathy produced by intravenous route. J Nerv Ment Dis. 1959;129:302-305.

48. Lumsden CE. Cyanide leukoencephalopathy in rats and observations on the vascular and ferment hypotheses of demyelinating diseases. J Neurol Neurosurg Psychiatry. 1950;13(1):1-15.

49. van Houten WH, Friede RL. Histochemical studies of experimental demyelination produced with cyanide. Exp Neurol. 1961;4:402-412.

50. Hurst EW. Experimental demyelination in relation to human and animal disease. Am J Med. 1952;12(5):547-560.

51. Levine S. Experimental cyanide encephalopathy: gradients of susceptibility in the corpus callosum. J Neuropathol Exp Neurol. 1967;26(2):214-222.

52. Evangelou N, Konz D, Esiri MM, Smith S, Palace J, Matthews PM. Regional axonal loss in the corpus callosum correlates with cerebral white matter lesion volume and distribution in multiple sclerosis. Brain. 2000;123(Pt 9):1845-1849.

53. Minagar A, Alexander JS. Blood-brain barrier disruption in multiple sclerosis. Mult Scler. 2003;9(6):540-549.

54. Hans FJ, Wei L, Bereczki D, et al. Nicotine increases microvascular blood flow and flow velocity in three groups of brain areas. Am J Physiol. 1993;265(6 Pt 2):H2142-H2150.

55. Grunwald F, Schrock H, Kuschinsky W. The influence of nicotine on local cerebral blood flow in rats. Neurosci Lett. 1991;124(1):108-110.

56. Chen JL, Wei L, Bereczki D, et al. Nicotine raises the influx of permeable solutes across the rat blood-brain barrier with little or no capillary recruitment. J Cereb Blood Flow Metab. 1995;15(4):687-698.

57. Hawkins BT, Abbruscato TJ, Egleton RD, et al. Nicotine increases in vivo blood-brain barrier permeability and alters cerebral microvascular tight junction protein distribution. Brain Res. 2004;1027(1-2): 48-58.
58. Hedstrom AK, Baarnhielm M, Olsson T, Alfredsson L. Tobacco smoking, but not Swedish snuff use, increases the risk of multiple sclerosis. Neurology. 2009;73(9):696-701.

59. Sopori ML, Kozak W. Immunomodulatory effects of cigarette smoke. J Neuroimmunol. 1998;83(1-2):148-156.

60. Floto RA, Smith KG. The vagus nerve, macrophages, and nicotine. Lancet. 2003;361(9363):1069-1070.

61. Guinet E, Yoshida K, Nouri-Shirazi M. Nicotinic environment affects the differentiation and functional maturation of monocytes derived dendritic cells (DCs). Immunol Lett. 2004;95(1):45-55.

62. Nouri-Shirazi M, Tinajero R, Guinet E. Nicotine alters the biological activities of developing mouse bone marrow-derived dendritic cells (DCs). Immunol Lett. 2007;109(2):155-164.

63. Francus T, Klein RF, Staiano-Coico L, Becker CG, Siskind GW. Effects of tobacco glycoprotein (TGP) on the immune system. II. TGP stimulates the proliferation of human T cells and the differentiation of human B cells into Ig secreting cells. J Immunol. 1988;140(6):1823-1829.

64. Shi FD, Piao WH, Kuo YP, Campagnolo DI, Vollmer TL, Lukas RJ. Nicotinic attenuation of central nervous system inflammation and autoimmunity. J Immunol. 2009;182(3):1730-1739.

65. Bij1 M, Horst G, Limburg PC, Kallenberg CG. Effects of smoking on activation markers, Fas expression and apoptosis of peripheral blood lymphocytes. Eur J Clin Invest. 2001;31(6):550-553.

66. Graeve L, Baumann M, Heinrich PC. Interleukin-6 in autoimmune disease. Role of IL-6 in physiology and pathology of the immune defense. Clin Investig. 1993;71(8):664-671.

67. Szalai AJ. C-reactive protein (CRP) and autoimmune disease: facts and conjectures. Clin Dev Immunol. 2004;11(3-4):221-226.

68. Ingram G, Hakobyan S, Robertson NP, Morgan BP. Complement in multiple sclerosis: its role in disease and potential as a biomarker. Clin Exp Immunol. 2009;155(2):128-139.

69. Lumsden CE. The immunogenesis of the multiple sclerosis plaque. Brain Res. 1971;28(3):365-390.

70. Tegla CA, Cudrici C, Rus V, et al. Neuroprotective effects of the complement terminal pathway during demyelination: implications for oligodendrocyte survival. J Neuroimmunol. 2009;213(1-2):3-11.

71. Robbins RA, Nelson KJ, Gossman GL, Koyama S, Rennard SI. Complement activation by cigarette smoke. Am J Physiol. 1991;260 (4 Pt 1):L254-259.

72. Volanakis JE, Kaplan MH. Interaction of C-reactive protein complexes with the complement system. II. Consumption of guinea pig complement by CRP complexes: requirement for human C1q. J Immunol. 1974;113(1):9-17.

73. Encinas JM, Manganas L, Enikolopov G. Nitric oxide and multiple sclerosis. Curr Neurol Neurosci Rep. 2005;5(3):232-238.

74. Clancy RM, Amin AR, Abramson SB. The role of nitric oxide in inflammation and immunity. Arthritis Rheum. 1998;41(7): 1141-1151.

75. Smith KJ, Kapoor R, Hall SM, Davies M. Electrically active axons degenerate when exposed to nitric oxide. Ann Neurol. 2001;49(4): 470-476.

76. Redford EJ, Kapoor R, Smith KJ. Nitric oxide donors reversibly block axonal conduction: demyelinated axons are especially susceptible. Brain. 1997;120(Pt 12):2149-2157.

77. Kapoor R, Davies M, Blaker PA, Hall SM, Smith KJ. Blockers of sodium and calcium entry protect axons from nitric oxide-mediated degeneration. Ann Neurol. 2003;53(2):174-180.

78. Oleszak EL, Zaczynska E, Bhattacharjee M, Butunoi C, Legido A, Katsetos CD. Inducible nitric oxide synthase and nitrotyrosine are found in monocytes/macrophages and/or astrocytes in acute, but not in chronic, multiple sclerosis. Clin Diagn Lab Immunol. 1998;5(4):438-445.

79. Liu JS, Zhao ML, Brosnan CF, Lee SC. Expression of inducible nitric oxide synthase and nitrotyrosine in multiple sclerosis lesions. $\mathrm{Am} \mathrm{J}$ Pathol. 2001;158(6):2057-2066.

80. Rejdak K, Eikelenboom MJ, Petzold A, et al. CSF nitric oxide metabolites are associated with activity and progression of multiple sclerosis. Neurology. 2004;63(8):1439-1445. 
81. Church DF, Pryor WA. Free-radical chemistry of cigarette smoke and its toxicological implications. Environ Health Perspect. 1985;64: 111-126.

82. Sarkar R, Gelabert HA, Mohiuddin KR, Thakor DK, SantibanezGallerani AS. Effect of cigarette smoke on endothelial regeneration in vivo and nitric oxide levels. J Surg Res. 1999;82(1):43-47.

83. Miller VM, Lewis DA, Rud KS, Offord KP, Croghan IT, Hurt RD. Plasma nitric oxide before and after smoking cessation with nicotine nasal spray. J Clin Pharmacol. 1998;38(1):22-27.

84. Zhou JF, Yan XF, Guo FZ, Sun NY, Qian ZJ, Ding DY. Effects of cigarette smoking and smoking cessation on plasma constituents and enzyme activities related to oxidative stress. Biomed Environ Sci. 2000;13(1):44-55.

85. Node K, Kitakaze M, Yoshikawa H, Kosaka H, Hori M. Reversible reduction in plasma concentration of nitric oxide induced by cigarette smoking in young adults. Am J Cardiol. 1997;79(11):1538-1541.

86. Graham NM. The epidemiology of acute respiratory infections in children and adults: a global perspective. Epidemiol Rev. 1990;12: 149-178.

87. Sibley WA, Bamford CR, Clark K. Clinical viral infections and multiple sclerosis. Lancet. 1985;325(8441):1313-1315.

88. Andersen O, Lygner PE, Bergstrom T, Andersson M, Vahlne A. Viral infections trigger multiple sclerosis relapses: a prospective seroepidemiological study. J Neurol. 1993;240(7):417-422.

89. Panitch HS. Influence of infection on exacerbations of multiple sclerosis. Ann Neurol. 1994;36 Suppl:S25-S28.

90. Edwards S, Zvartau M, Clarke H, Irving W, Blumhardt LD. Clinical relapses and disease activity on magnetic resonance imaging associated with viral upper respiratory tract infections in multiple sclerosis J Neurol Neurosurg Psychiatry. 1998;64(6):736-741.

91. Buljevac D, Flach HZ, Hop WC, et al. Prospective study on the relationship between infections and multiple sclerosis exacerbations. Brain. 2002;125(Pt 5):952-960.

92. Sriram S, Stratton CW, Yao S, et al. Chlamydia pneumoniae infection of the central nervous system in multiple sclerosis. Ann Neurol. 1999; 46(1):6-14.

93. Parratt J, Tavendale R, O’Riordan J, Parratt D, Swingler R. Chlamydia pneumoniae-specific serum immune complexes in patients with multiple sclerosis. Mult Scler. 2008;14(3):292-299.

94. Budak F, Keceli S, Efendi H, Vahaboglu H. The investigation of Chlamydophila pneumoniae in patients with multiple sclerosis. Int $J$ Neurosci. 2007;117(3):409-415.

95. Boman J, Roblin PM, Sundstrom P, Sandstrom M, Hammerschlag MR. Failure to detect Chlamydia pneumoniae in the central nervous system of patients with MS. Neurology. 2000;54(1):265.

96. Karvonen M, Tuomilehto J, Pitkaniemi J, Naukkarinen A, Saikku P. Importance of smoking for Chlamydia pneumoniae seropositivity. Int J Epidemiol. 1994;23(6):1315-1321.

97. Ridker PM, Kundsin RB, Stampfer MJ, Poulin S, Hennekens CH. Prospective study of Chlamydia pneumoniae IgG seropositivity and risks of future myocardial infarction. Circulation. 1999;99(9):1161-1164.

98. Ascherio A, Munger KL. Environmental risk factors for multiple sclerosis. Part I: the role of infection. Ann Neurol. 2007;61(4):288-299.

99. Nielsen TR, Pedersen M, Rostgaard K, Frisch M, Hjalgrim H. Correlations between Epstein-Barr virus antibody levels and risk factors for multiple sclerosis in healthy individuals. Mult Scler. 2007;13(3):420-423.

100. Farrell RA, Antony D, Wall GR, et al. Humoral immune response to EBV in multiple sclerosis is associated with disease activity on MRI. Neurology. 2009;73(1):32-38.

101. Rosenberg GA. Matrix metalloproteinases biomarkers in multiple sclerosis. Lancet. 2005;365(9467):1291-1293.

102. Lee MA, Palace J, Stabler G, Ford J, Gearing A, Miller K. Serum gelatinase B, TIMP-1 and TIMP-2 levels in multiple sclerosis. A longitudinal clinical and MRI study. Brain. 1999;122(Pt 2):191-197.

103. Nakamura T, Ebihara I, Shimada N, Koide H. Effect of cigarette smoking on plasma metalloproteinase-9 concentration. Clin Chim Acta. 1998;276(2):173-177.
104. Sfagos C, Makis AC, Chaidos A, et al. Serum ferritin, transferrin and soluble transferrin receptor levels in multiple sclerosis patients. Mult Scler. 2005;11(3):272-275.

105. Abo-Krysha N, Rashed L. The role of iron dysregulation in the pathogenesis of multiple sclerosis: an Egyptian study. Mult Scler. 2008;14(5):602-608.

106. Gutteridge JM. Iron and oxygen radicals in brain. Ann Neurol. 1992;32 Suppl:S16-S21.

107. Halliwell B, Gutteridge JM. Oxygen toxicity, oxygen radicals, transition metals and disease. Biochem J. 1984;219(1):1-14.

108. Borg DC. Oxygen free radicals and tissue injury. A reference outline. In: Tarr M, Samson F, editors. Oxygen Free Radicals in Tissue Damage. Boston: Birkhauser; 1993:12-53.

109. Borg DC, Schaich KM. Iron and iron-derived radicals. In: Halliwell B, editor. Oxygen Radicals and Tissue Injury. Bethesda, MD: Federation of American Societies for Experimental Biology; 1998: 20-26.

110. El-Zayadi AR, Selim O, Hamdy H, El-Tawil A, Moustafa H. Heavy cigarette smoking induces hypoxic polycythemia (erythrocytosis) and hyperuricemia in chronic hepatitis $\mathrm{C}$ patients with reversal of clinical symptoms and laboratory parameters with therapeutic phlebotomy. Am J Gastroenterol. 2002;97(5):1264-1265.

111. Padmavathi P, Reddy VD, Varadacharyulu N. Influence of chronic cigarette smoking on serum biochemical profile in male human volunteers. J Health Sci. 2009;55(2):265-270.

112. Bernhard D, Rossmann A, Wick G. Metals in cigarette smoke. IUBMB Life. 2005;57(12):805-809.

113. Suzuki T, Shishido S, Urushiyama K. Mercury in cigarettes. Tohoku J Exp Med. 1976;119(4):353-356.

114. Krigman MR. Neuropathology of heavy metal intoxication. Environ Health Perspect. 1978;26:117-120.

115. Dringen R, Bishop GM, Koeppe M, Dang TN, Robinson SR. The pivotal role of astrocytes in the metabolism of iron in the brain. Neurochem Res. 2007;32(11):1884-1890.

116. Tiffany-Castiglion E, Qian Y. Astroglia as metal depots: molecular mechanisms for metal accumulation, storage and release. Neurotoxicology. 2001;22(5):577-592.

117. Valberg LS, Flanagan PR, Kertesz A, Ebers GC. Abnormalities in iron metabolism in multiple sclerosis. Can J Neurol Sci. 1989;16(2): 184-186.

118. Haacke EM, Cheng NY, House MJ, et al. Imaging iron stores in the brain using magnetic resonance imaging. Magn Reson Imaging. 2005;23(1):1-25.

119. Toshniwal PK, Zarling EJ. Evidence for increased lipid peroxidation in multiple sclerosis. Neurochem Res. 1992;17(2):205-207.

120. LeVine SM. Iron deposits in multiple sclerosis and Alzheimer's disease brains. Brain Res. 1997;760(1-2):298-303.

121. Kermode AG, Thompson AJ, Tofts P, et al. Breakdown of the bloodbrain barrier precedes symptoms and other MRI signs of new lesions in multiple sclerosis. Pathogenetic and clinical implications. Brain. 1990;113(Pt 5):1477-1489.

122. Tan IL, van Schijndel RA, Pouwels PJ, et al. MR venography of multiple sclerosis. AJNR Am J Neuroradiol. 2000;21(6):1039-1042.

123. Zamboni P, Galeotti R, Menegatti E, et al. Chronic cerebrospinal venous insufficiency in patients with multiple sclerosis. J Neurol Neurosurg Psychiatry. 2009;80(4):392-399.

124. Zamboni P. The big idea: iron-dependent inflammation in venous disease and proposed parallels in multiple sclerosis. $J$ R Soc Med. 2006;99(11):589-593.

125. Zamboni P, Menegatti E, Galeotti R, et al. The value of cerebral Doppler venous haemodynamics in the assessment of multiple sclerosis. J Neurol Sci. 2009;282(1-2):21-27.

126. Zivadinov R, Marr K, Ramanathan M, et al. Combined transcranial and extracranial venous doppler evaluation (CTEVD Study). Description of the design and interim results of an epidemiological study of the prevalence of chronic cerebrospinal venous insufficiency in MS and related diseases. Neurology. 2010;74 (Supp1 2):A545. 
127. Gourgou S, Dedieu F, Sancho-Garnier H. Lower limb venous insufficiency and tobacco smoking: a case-control study. Am J Epidemiol. 2002;155(11):1007-1015.

128. Hickey RJ, Clelland RC, Boyce DE. Carbon monoxide: smoking, air pollution, cardiovascular disease, and physiological homoeostasis. Lancet. 1973;2(7828):571-572.

129. Michiels C, Arnould T, Remacle J. Hypoxia-induced activation of endothelial cells as a possible cause of venous diseases: hypothesis. Angiology. 1993;44(8):639-646.

130. Higman DJ, Powell JT, Greenhalgh RM, Coady A, Moss J. Is thickening of the basal lamina in the saphenous vein a hallmark of smoking? Br Heart J. 1994;71(1):45-50.

131. Higman DJ, Greenhalgh RM, Powell JT. Smoking impairs endothelium-dependent relaxation of saphenous vein. Br J Surg. 1993; 80(10):1242-1245.

132. Lee AB, Laredo J, Neville R. Embryological background of truncular venous malformation in the extracranial venous pathways as the cause of chronic cerebro spinal venous insufficiency. Int Angiol. 2010;29(2):95-108.

133. Myhr KM. Vitamin D treatment in multiple sclerosis. J Neurol Sci. 2009;286(1-2):104-108.

134. Morabia A, Bernstein MS, Antonini S. Smoking, dietary calcium and vitamin D deficiency in women: a population-based study. Eur J Clin Nutr. 2000;54(9):684-689.

135. Brot C, Jorgensen NR, Sorensen OH. The influence of smoking on vitamin D status and calcium metabolism. Eur J Clin Nutr. 1999; 53(12):920-926.

136. Tremlett H, van der Mei IA, Pittas F, et al. Monthly ambient sunlight, infections and relapse rates in multiple sclerosis. Neuroepidemiology. 2008;31(4):271-279.

137. Istvan J, Matarazzo JD. Tobacco, alcohol, and caffeine use: a review of their interrelationships. Psychol Bull. 1984;95(2):301-326.

138. Tang J, Muir J, Lancaster T, Jones L, Fowler G. Health profiles of current and former smokers and lifelong abstainers. OXCHECK Study Group. OXford and Collaborators HEalth ChecK. J R Coll Physicians Lond. 1997;31(3):304-309.

139. Tola MR, Granieri E, Malagu S, et al. Dietary habits and multiple sclerosis. A retrospective study in Ferrara, Italy. Acta Neurol (Napoli). 1994;16(4):189-197.

140. Pekmezovic T, Drulovic J, Milenkovic M, et al. Lifestyle factors and multiple sclerosis: a case-control study in Belgrade. Neuroepidemiology. 2006;27(4):212-216.

141. Goodin DS. Survey of multiple sclerosis in northern California. Northern California MS Study Group. Mult Scler. 1999;5(2):78-88.

142. Prakash RS, Snook EM, Erickson KI, et al. Cardiorespiratory fitness: a predictor of cortical plasticity in multiple sclerosis. Neuroimage. 2007;34(3):1238-1244.

143. Cade JE, Margetts BM. Relationship between diet and smoking - is the diet of smokers different? J Epidemiol Community Health. 1991;45(4):270-272.

144. Zhang SM, Willett WC, Hernan MA, Olek MJ, Ascherio A. Dietary fat in relation to risk of multiple sclerosis among two large cohorts of women. Am J Epidemiol. 2000;152(11):1056-1064.
145. Farinotti M, Simi S, Di Pietrantonj C, et al. Dietary interventions for multiple sclerosis. Cochrane Database Syst Rev. 2007(1): CD004192.

146. Zhang SM, Hernan MA, Olek MJ, Spiegelman D, Willett WC, Ascherio A. Intakes of carotenoids, vitamin C, and vitamin E and MS risk among two large cohorts of women. Neurology. 2001;57(1):75-80.

147. Bamia C, Trichopoulou A, Lenas D, Trichopoulos D. Tobacco smoking in relation to body fat mass and distribution in a general population sample. Int J Obes Relat Metab Disord. 2004;28(8):1091-1096.

148. Munger KL, Chitnis T, Ascherio A. Body size and risk of MS in two cohorts of US women. Neurology. 2009;73(19):1543-1550.

149. Fergusson DM, Lynskey MT, Horwood LJ. Comorbidity between depressive disorders and nicotine dependence in a cohort of 16-year-olds. Arch Gen Psychiatry. 1996;53(11):1043-1047.

150. Siegert RJ, Abernethy DA. Depression in multiple sclerosis: a review. J Neurol Neurosurg Psychiatry. 2005;76(4):469-475.

151. Marrie RA, Horwitz R, Cutter G, Tyry T, Campagnolo D, Vollmer T. Comorbidity delays diagnosis and increases disability at diagnosis in MS. Neurology. 2009;72(2):117-124.

152. Marrie RA, Rudick R, Horwitz R, et al. Vascular comorbidity is associated with more rapid disability progression in multiple sclerosis. Neurology. 2010;74(13):1041-1047.

153. Lynch JR, Tang W, Wang H, et al. APOE genotype and an ApoEmimetic peptide modify the systemic and central nervous system inflammatory response. J Biol Chem. 2003;278(49):48529-48533.

154. Sena A, Couderc R, Ferret-Sena V, et al. Apolipoprotein E polymorphism interacts with cigarette smoking in progression of multiple sclerosis. Eur J Neurol. 2009;16(7):832-837.

155. Reitz C, den Heijer T, van Duijn C, Hofman A, Breteler MM. Relation between smoking and risk of dementia and Alzheimer disease: the Rotterdam Study. Neurology. 2007;69(10):998-1005.

156. Singh R, Barden A, Mori T, Beilin L. Advanced glycation endproducts: a review. Diabetologia. 2001;44(2):129-146.

157. Goldin A, Beckman JA, Schmidt AM, Creager MA. Advanced glycation end products: sparking the development of diabetic vascular injury. Circulation. 2006;114(6):597-605.

158. Hofmann MA, Drury S, Fu C, et al. RAGE mediates a novel proinflammatory axis: a central cell surface receptor for $\mathrm{S} 100$ / calgranulin polypeptides. Cell. 1999;97(7):889-901.

159. Schmidt AM, Yan SD, Yan SF, Stern DM. The multiligand receptor RAGE as a progression factor amplifying immune and inflammatory responses. J Clin Invest. 2001;108(7):949-955.

160. Sternberg Z, Weinstock-Guttman B, Hojnacki D, et al. Soluble receptor for advanced glycation end products in multiple sclerosis: a potential marker of disease severity. Mult Scler. 2008;14(6):759-763.

161. Yan SS, WuZY,Zhang HP, et al. Suppression of experimental autoimmune encephalomyelitis by selective blockade of encephalitogenic T-cell infiltration of the central nervous system. Nat Med. 2003;9(3):287-293.

162. Vazzana N, Santilli F, Cuccurullo C, Davi G. Soluble forms of RAGE in internal medicine. Intern Emerg Med. 2009;4(5):389-401.

163. Cerami C, Founds H, Nicholl I, et al. Tobacco smoke is a source of toxic reactive glycation products. Proc Natl Acad Sci U S A. 1997; 94(25):13915-13920.
Journal of Inflammation Research

\section{Publish your work in this journal}

The Journal of Inflammation Research is an international, peer-reviewed open-access journal that welcomes laboratory and clinical findings on the molecular basis, cell biology and pharmacology of inflammation including original research, reviews, symposium reports, hypothesis formation and commentaries on: acute/chronic inflammation; mediators of inflamma-

\section{Dovepress}

tion; cellular processes; molecular mechanisms; pharmacology and novel anti-inflammatory drugs; clinical conditions involving inflammation. The manuscript management system is completely online and includes a very quick and fair peer-review system. Visit http://www.dovepress.com/ testimonials.php to read real quotes from published authors. 